\title{
El orden y la variedad de la creación. Una aproximación a la teoría cartesiana de la sustancia
}

\section{Order and Variety of Creation. An Approach to the Cartesian Theory of Substance}

\author{
Pedro LOMBA FALCÓN \\ Universidad Complutense de Madrid
}

Recibido: 02-06-2011

Aceptado: 10-07-2011

\section{Resumen}

En este artículo se ensaya, por un lado, un examen de la reflexión cartesiana sobre el concepto de sustancia -reflexión que cristaliza en una teoría difusa, dispersa en múltiples pasajes de su obra- subrayando sus puntos más problemáticos (aquellos sobre los cuales la filosofía postcartesiana del XVII se verá obligada a posicionarse, siempre críticamente), $\mathrm{y}$, por otro, un análisis de la manera como la teoría que Descartes construye a propósito de dicho concepto hace plenamente visibles los principios fundamentales que gobiernan la progresiva constitución de su metafísica: el creacionismo divino y las lógicas que éste implica (equivocismo y analogía).

Palabras clave: Descartes, Sustancia, voluntad, analogía, creacionismo, libertad.

\begin{abstract}
In this article, the author tries, on one hand, to examine the Cartesian reflection about the concept of substance, underlining its very problematic points (those about which the postcartesian philosophy of the second half of XVIIth century will be
\end{abstract}


obliged to take a position), and, on the other, to analyze how the theory Descartes constructs starting from this concept, shows clearly the fundamental principles on which he constructs the whole of his Metaphysics. This principles are no others than divin creationism and the logics it necessarily implies: analogy and equivocism.

Keywords: Descartes, Substance, Free will, Analogy, Creationism, Freedom.

Tal vez pueda afirmarse que buena parte de la especificidad de la gran filosofía moderna se debe a su trabajo de redefinición de algunas de las categorías en torno a las cuales se había configurado la reflexión filosófica en épocas anteriores al siglo XVII. Es decir, al trabajo de índole conceptual al que ciertamente se entregaron los responsables de la construcción de esa «nueva filosofía» cuya pretensión más emblemática fue -paradójicamente en apariencia- la de liquidar de una vez por todas, confinándolas al terreno de la pura insignificancia, las formas consideradas como más representativas del saber propio del pasado. Semejante esfuerzo de reforma de ciertos conceptos perfectamente clásicos, tradicionales, los habría transformado de un modo decisivo, reactivando así su potencia. Por ello, lo propio de la Modernidad podría medirse según el rasero de la generación de nuevos sentidos y de nuevas polémicas, capaces de actualizar con eficacia, de una manera u otra, los materiales quizás ya demasiado gastados con los que se ha construido la reflexión filosófica durante ese pasado que ahora se pretende cancelar. Lo realmente nuevo en la llamada «nueva filosofía» podría reconocerse, por tanto, en el sentido y en las funciones que esas categorías asumidas como legado adquieren y cumplen en la construcción de los sistemas filosóficos del momento, de modo que podría afirmarse que éstos suponen verdaderamente una ruptura aun cuando los conceptos con los que está tejida su trama no parezcan novedosos. La cifra del novum más general de la Modernidad no estaría entonces en un desprecio total de la herencia recibida, sino en la exigencia de gestionarla de una manera inaudita: estaría en la redefinición, en el uso y en la organización de aquellos viejos conceptos en función de polémicas nunca antes entabladas, o de polémicas que ahora se emprenden a propósito de otros interrogantes. La especificidad de lo «moderno» residiría, así, en un esfuerzo consciente por acuñar una forma realmente inaugural para el pensamiento.

Acaso pueda señalarse un momento eminente de este tipo de trabajo en el empleo que hace Descartes del concepto tradicional de sustancia y en la teoría -fragmentaria, dispersa en diversos pasajes de su obra- que con él construye, pues es a su amparo como va a ir proponiendo muchas de las ideas fundamentales que dan un contenido a su metafísica, auténtico arcano de la forma «moderna» del pensamiento a que estoy aludiendo. Por ejemplo, la demostración de la existencia de Dios desde una de las ideas que el cogito encuentra en sí mismo, su teoría de la cre- 
ación continua, su influyente y problemático sistema de la libertad, o su doctrina -absolutamente fundacional, en muchos aspectos, del nuevo espacio teórico que se abre en el XVII- acerca del especial estatuto ontológico que la voluntad, más que el entendimiento, otorga a los hombres frente al resto de las cosas de la naturaleza.

Mi propósito en estas páginas será el de examinar la difusa teoría que Descartes construye con dicho concepto, subrayando sus puntos más problemáticos -aquellos sobre los cuales la filosofía del siglo se verá obligada a posicionarse, siempre de manera crítica, los acepte o los rechace-, y, a la vez, el de tratar de analizar cómo la reflexión de nuestro autor sobre tal noción hace plenamente visible un principio que gobierna con mano muy firme la progresiva constitución de la arquitectónica de su sistema. Me refiero al creacionismo divino, principio heredado de la tradición filosófica cristiana más pregnante -al igual que la lógica que dicho creacionismo exige y que también vertebra la teoría cartesiana de la sustancia: la lógica de la equivocidad y unida a ella, aunque de una manera compleja y peculiar, la de la analogía-, pero del que el francés hace un uso que determina la estructura de un sistema cuyos contenidos y cuya manera de ordenarlos forja, más allá de toda duda razonable, la forma de ese horizonte intelectual moderno que se percibe a sí mismo como la definitiva liquidación de la filosofía del pasado y también, en consecuencia, de la significatividad de su memoria. Descartes construye así, mediante el creacionismo, la equivocidad y la analogía - a pesar de su aparentemente escasa carga de «modernidad»-, el espacio teórico general dentro del cual se desarrollará su metafísica. Espacio, por ello mismo, en cuya exploración y profundización adquirirá su forma y su sentido propios la filosofía más sistemática del XVII. Vayamos por partes.

\section{Variedad y sustancialidad de la creación. Teoría de la equivocidad}

Si examinamos los dos lugares en que Descartes reflexiona más ordenadamente sobre el concepto de sustancia ${ }^{1}$, podemos comprobar que en ellos son ofrecidas dos definiciones que aparentemente difieren entre sí pero que se complementan

\footnotetext{
1 Nos referimos a la parte final de las Réponses de l'auteur aux secondes objections, parte que lleva por título Raisons qui prouvent l'existence de Dieu et la distinction qui est entre l'esprit et le corps humain disposées d'une façon géométrique (AT, IX-1, 124-132), y a los arts. 51-54 de la primera parte de los Principes de la philosophie (AT, IX-2, 46-48). Sobre la teoría cartesiana de la sustancia, cf. los estudios específicos de J.-M. Beyssade, «La théorie cartésienne de la substance. Équivocité ou analogie?», en id. : Études sur Descartes. L'histoire d'un esprit, París, Seuil, 2001, pp. 217-244, y J.-L. MARION, «Substance et subsistance. Suarez et le traité de la substantia dans les Principia philosophiae, I § 51-54», ahora en id., Questions cartésiennes (vol. 2), París, P.U.F., 1996, cap. 3. Citamos las obras de Descartes según la edición de Charles Adam y Paul Tannery (Euvres de Descartes, París, Vrin, 1996 (1897-1913), 11vols.), siguiendo la costumbre de consignar la abreviatura AT seguida del número de volumen en romanos y el de página en arábigos. Todas las traducciones son nuestras.
} 
delimitando con claridad el horizonte dentro del que va a desarrollarse su teoría. En primer lugar, en las Meditaciones metafisicas se propone una definición que tiene mucho de tradicional y que recoge dos de los caracteres fundamentales de la formulada por Aristóteles:

Toda cosa en la que reside inmediatamente, como en su sujeto, o por la cual existe algo que concebimos, es decir, alguna propiedad, cualidad, o atributo, del que tenemos en nosotros una idea real, se llama sustancia ${ }^{2}$

Ésta es definida como sujeto o sustrato de propiedades, cualidades o atributos. Inherencia y predicación, por tanto, como sus dos notas esenciales. Creemos que estos dos caracteres son seleccionados aquí porque la definición que con ellos se construye sirve perfectamente a la estrategia discursiva desplegada en este escrito. Puesto que de lo que se trata en esta meditación tercera es, fundamentalmente, de demostrar la existencia de Dios, se puede definir la sustancia como sustrato o sujeto productor, por ejemplo, de ideas, y principalmente de una determinada idea de Dios contenida en el cogito. Y se puede, además, como veremos más abajo, definir el alma, el cuerpo y a Dios como sustancias apelando indirectamente a una cierta analogía. Con el término sustancia, así pues, es propuesta una definición general a partir de la cual van a ser establecidas tres definiciones especiales para los tres tipos distintos de sustancia que constituyen, por así decir, los tres vértices sobre los que se asienta la metafísica de las Meditaciones.

Sin embargo, si examinamos la definición que Descartes ofrece en los Principios de la filosofía, constatamos enseguida que la propuesta en las Meditaciones es modificada mediante una suerte de ampliación, de manera que ahora se cumple explícitamente con al menos uno de los criterios que también iba de suyo en la tradición aristotélica pero que había sido dejado de lado en el texto citado anteriormente: el de la inseidad, la cual es pensada en este momento de la reflexión, legítimamente, como perseidad ${ }^{3}$. En el artículo 51 de su primera parte leemos que

Cuando concebimos la sustancia, concebimos solamente una cosa que existe de tal manera que sólo precisa de sí misma para existir. ${ }^{4}$

Concebir una sustancia es, en este otro momento de la teoría, concebir algo que existe por sí; es concebir una modalidad del existir absolutamente autosuficiente:

\footnotetext{
2 AT, IX-1, 125.

3 Cf. J.-L. Marion, Sur la théologie blanche de Descartes. Analogie, création des vérités éternelles et fondement, París, P.U.F., 1991 (1981), p. 110.

${ }^{4}$ AT, IX-2, 47.
} 
sustancia es aquello que sólo precisa de sí mismo para ser; ésta es definida ahora por su autonomía, por su independencia o autosuficiencia ontológica.

Lo realmente significativo es que en este pasaje se añade una explicación que pone al descubierto la lógica que va a determinar la forma, el contenido y las consecuencias fundamentales de la teoría cartesiana de la sustancia. Nuestro autor apela inmediatamente después de haber definido así el concepto a una cierta «equivocidad» que dará el tono de su metafísica entera. La hipótesis que manejaremos es doble. Por un lado, consideramos que ambas definiciones son necesariamente complementarias: su conjugación es lo que permitirá al francés desarrollar una teoría compleja - articulada según dos usos o momentos de la lógica de la analogía- acerca de la variedad y la estructura o el orden del mundo. Por otro, tenemos la convicción de que tanto la equivocidad presente en el artículo citado de los Principios como la analogía que pide la definición ofrecida en el pasaje de las Meditaciones que hemos convocado antes, vienen exigidas por el principio que sostiene la arquitectónica del sistema cartesiano todo: el creacionismo divino. Para desarrollar ambas hipótesis empezaremos tratando de comprender cuáles han podido ser las razones que han llevado a Descartes a definir la sustancia tal como lo hace en la primera parte de los Principios de la filosofía. Es preciso, pues, acotar los envites de esa lógica de la equivocidad que determina en este texto su compleja teoría de la sustancia.

Por una parte, «sustancia», tal y como es definida en el artículo 51, sólo puede ser, «propiamente hablando», aquello que existe por sí, aquello que de ninguna causa, de nada exterior a sí mismo, necesita para existir; aquello que es per se:

[...] propiamente hablando, sólo Dios es tal, y no hay ninguna cosa creada que pueda existir un solo momento sin ser sostenida y conservada por su potencia. 5

En sentido propio, sólo de Dios podemos decir que es sustancia. Sólo Dios necesita únicamente de sí para existir -lo cual, dicho sea de paso, será lo que exija que Dios haya de ser definido como causa sui6-. Una vez asentado este principio, el concepto es pensado según una cierta lógica de la equivocidad que se quiere absolutamente imprescindible; ella es la responsable directa del desarrollo de esta teoría de la sustancia - con dicha lógica puede ampliarse decisivamente el campo semántico del concepto-:

\footnotetext{
5 AT, IX-2, 47.

${ }^{6} \mathrm{Cf}$. las cuartas objeciones de Arnauld a las Meditaciones metafisicas (AT, IX-1, 160-167), con sus respuestas (AT, IX-1, 179-190).
} 
Es por ello por lo que tiene razón la Escuela cuando dice que el nombre de sustancia no es «unívoco» en relación a Dios y a las criaturas. ${ }^{7}$

En lugar, pues, de reservar única y exclusivamente el nombre de sustancia a Dios, único ente del que se puede decir «propiamente» que existe en sí y por sí, concesión a «la Escuela», aunque sólo sea a propósito de la necesaria equivocidad con que debe predicarse el término «sustancia» si se pretende predicarlo también de algunas criaturas. O si, mejor que de una pretensión, de lo que se trata es de una necesidad dictada por los principios de una determinada ontología, necesidad que obviamente convierte en legítima dicha equivocidad ${ }^{8}$. Esas cosas de las que es legítimo afirmar que son sustancias, dado que necesariamente son cosas creadas, no pueden existir un solo momento, como dice este texto y Descartes no se ha cansado de repetir en toda su obra, al menos desde la primavera de 16309 , «sin ser sostenidas y conservadas» por la potencia de Dios. «Sustancia» será, entonces, un nombre aplicable no sólo a aquello que es único y cuya consistencia ontológica es completa; se convierte en un concepto a cuyo través pueden pensarse los dos planos fundamentales de lo real: el del principio de todo lo que es -Dios, absolutamente trascendente, por tanto, al mundo-, y el de las cosas creadas -el de aquellas cuya esencia y cuya existencia precisan de un principio exterior a sí mismas-. La teoría de la sustancia constituye, indiscutiblemente, una de las formas que adopta la reflexión de Descartes - transversal a toda su obra- sobre la potencia de Dios y las criaturas.

En efecto, tenemos que preguntarnos a qué puede deberse esta ampliación, este desdoblamiento de la definición propuesta. Y tal vez sólo podamos responder afirmando que dicha extensión del campo semántico del concepto de sustancia se debe al peso que la tradición ejerce sobre el pensamiento de la perseidad, pues, como ha señalado Jean-Luc Marion ${ }^{10}$, se trata de un pensamiento muy sobredeterminado ya por la concepción cristiana de la creación -concepción ésta que en Descartes, a su vez, sobredetermina además su propia reflexión sobre la verdad11-. Esto es, al peso ejercido por un pensamiento que se remite ya de manera espontánea, inmediata, a la noción de un Dios creador y, por tanto, esencialmente trascendente. En sentido estricto, sólo el principio creador de todo lo que es, es per se, dependiendo todas las demás sustancias que podamos localizar en el ámbito de lo creado de la sustancia creadora que las instaura. Y que las instaura -esto es lo esencial- en su sustanciali-

\footnotetext{
7 Ibid.

8 Cf. J.-M. Beyssade, Études sur Descartes, op. cit., p. 233.

${ }^{9}$ Cf. la correspondencia de Descartes con Mersenne de la primavera de 1630, de la cual diremos algo más adelante (AT, I, 135-154).

10 Cf. J.-L. Marion, Sur la théologie blanche de Descartes, op. cit., pp. 110-111.

${ }^{11} \mathrm{Cf}$. la correspondencia sobre la creación divina de las verdades eternas a la que remitimos dos notas más arriba.
} 
dad misma. De ahí que la perseidad pueda ser entendida también -y a la demostración de ello se entrega Descartes inmediatamente- como la relativa suficiencia o autonomía de la sustancia creada por oposición a la insuficiencia del atributo, de la cualidad, del modo. Ciertamente, la sustancialidad designa en sentido propio una autonomía interna; pero también, y al mismo tiempo, casi automáticamente debido a la función desempeñada por el creacionismo cartesiano, el necesario concurso ordinario, externo y directo, del Creador de todo lo que es respecto de lo creado. O, más precisamente, respecto de ciertas cosas creadas. Éste es el principio que da sentido aquí al uso de la lógica de la equivocidad.

Es por ello por lo que el francés -así cierra este artículo 51 de los Principiospasa de inmediato a determinar de cuáles de entre las criaturas puede predicarse -equívocamente, por supuesto- el mismo término que conviene eminentemente a Dios:

[...] porque entre las cosas creadas algunas son de tal naturaleza que no pueden existir sin algunas otras, nosotros las distinguimos de aquellas que sólo tienen necesidad del concurso ordinario de Dios llamando a éstas sustancias, y a aquéllas cualidades o atributos de estas sustancias ${ }^{12}$

Tal término no designa a todos los tipos de cosas creadas. Conviene solamente a aquellas cuya existencia mantiene una especial relación de dependencia directa y única con su creador. Con lo cual, el esquema de nuestra comprensión del mundo se distribuye en función del tipo de relación que guarden las cosas que lo pueblan con el fundamento ontológico de su existencia -y también de su esencia-: las hay que precisan de otras criaturas para existir, además de depender, por supuesto, de Dios - esto es, cosas cuya dependencia ontológica es doble y cuya relación con Dios es, por tanto, indirecta-, y otras que tan sólo precisan del concurso ordinario e inmediato de la potencia de Dios para existir -aquellas cuya existencia depende única y directamente, sin intermediación alguna, de Dios y que pueden ser por ello, en cierto sentido equívoco, principio del ser de las demás-. A unas se les puede atribuir el nombre de sustancia; a las otras no.

De esta manera, en el artículo siguiente, el 52, es explicitado el sentido de la sustancialidad. A pesar de que, en rigor, el concepto tiene un significado preciso y determinado, no obstante, ciertas cosas entre las criaturas pueden ser llamadas «sustancias»:

[...] sólo es necesario, para entender que son sustancias, que percibamos que pueden existir sin la ayuda de ninguna otra cosa creada 13

\footnotetext{
12 AT, IX-2, 47.
}

13 AT, IX-2, 47, 
La sustancialidad «equívoca» de ciertas criaturas reproduce en alguna medida la autosuficiencia de su principio. Designa una forma de autosuficiencia, pero secundaria o mitigada: autosuficiencia sólo en el interior del mundo creado. La equivocidad se ve como doblada de una cierta analogía. Pensar las sustancias creadas exige reconocer en ellas algo análogo a la absoluta autosuficiencia de Diosi4; algo, por tanto, que indique su autosuficiencia, pero que, a la vez, establezca un límite infranqueable que impida pensarla como absoluta. Las sustancias creadas son en algún sentido, como Dios, autosuficientes, sí; pero sólo en relación a otras sustancias creadas. El alma, por ejemplo, no precisa del cuerpo para ser, pero precisa, para ser y para subsistir, de la potencia trascendente de Dios, de su «concurso ordinario». En este último sentido, pero sólo en éste, las diferencias entre las sustancias creadas y el resto de entes o cosas del mundo de la creación quedarían como anuladas: todo precisa, para existir y mantener su existencia, de la potencia de Dios. Todo lo que es, no siendo Dios, es por su propia esencia -aunque no exactamente de la misma manera- indigente o impotente; todo está como ecualizado en su insuficiencia ontológica. Por ello podrá recuperarse, dentro siempre de los límites de lo creado, un cierto univocismo. Aunque sólo por lo que hace a las sustancias. La indigencia ontológica de las cosas del mundo -su esencial impotencia para ser y para perseverar en el ser- parece admitir grados.

Así pues, la articulación de esta reflexión primera, general, sobre el concepto conduce directamente al establecimiento de un orden estricto; es decir, señala una variedad de principio. La reflexión establece con firmeza un orden entre las cosas cuya existencia depende de la potencia divina. Orden que, obviamente, se convierte en criterio de la variedad, de la diversidad de aquellas cosas del mundo, y que se establece, como ponen de manifiesto estos textos, según un principio de autosuficiencia o autonomía. Con tal criterio queda fundamentada una gradación que parte de lo que sólo necesita de sí mismo para existir y se revela como principio creador de todas las cosas -sustancia en sentido propio o Dios: grado absoluto de autonomía o autosuficiencia-, que continúa con las cosas creadas que tan sólo precisan del concurso ordinario de Dios y que, por tanto, pueden existir independientemente de otros tipos de cosas creadas -sustancias en sentido equívoco o derivado: grado intermedio de autosuficiencia-, y que termina en las cosas creadas cuya existencia depende de otras cosas creadas -atributos, o propiedades, o modos: grado ínfimo de autosuficiencia o de autonomía-. El criterio de la sustancialidad, en este primer momento de la reflexión, impone la necesidad de pensar el mundo, su variedad real, como un orden que transcribe una jerarquía ontológica general. El concepto de sustancia conduce al trazado de una suerte de cartografía completa, aunque abstracta, del mundo de la creación. Para ello basta con tomar un concepto tradicional de la

14 Cf. J.-M. Beyssade, Études sur Descartes, op. cit., p. 219. 
metafísica y pensarlo según esa lógica de la equivocidad exigida por el peso que en la reflexión tiene el creacionismo. Tal parece ser el primer rendimiento significativo de esta teoría. Al menos por lo que se refiere a los Principios.

En efecto, Descartes introduce dicha noción, en el desarrollo conceptual que prepara y conduce a la doble definición de sustancia de los artículos 51 y 52, como rasero según el cual establecer distinciones en la amalgama de cosas creadas que se ofrece al conocimiento. O, mejor, a la experiencia:

Y la principal distinción que observo entre todas las cosas creadas, es que unas son intelectuales, es decir, sustancias inteligentes, o propiedades que pertenecen a estas sustancias, y otras son corporales, es decir, que son cuerpos o propiedades que pertenecen al cuerpo. 15

La principal distinción que constatamos dentro de la creación es la que permite dividir o distinguir el conjunto de cosas creadas, por un lado, en sustancias, y, por otro, en atributos, o propiedades, o modos. Y dentro del conjunto de las sustancias creadas parece insoslayable el reconocimiento de una distinción real entre ellas: entre sustancias «intelectuales» y sustancias «corporales». Esto es, Descartes utiliza aquí el término «sustancia» para referirse a dos tipos de cosas creadas realmente distintas -aunque en principio, y por el momento, nada se afirme sobre su diferente estatuto ontológico-, reservando a Dios el papel de condición trascendente y permanente de su sustancialidad. Así, el esquema de la teoría, tal como aquí se ofrece, podría presentarse de la siguiente manera: la sustancia en sentido propio crea otras sustancias, las cuales pueden ser denominadas «sustancias»

a/ por precisar del concurso divino - de la voluntad de Dios-, y sólo de él, para existir;

b/ por ser ontológicamente independientes las unas de las otras; y

c/ por poseer determinadas propiedades, o atributos, o modos, ${ }^{16}$ sólo a partir de

\begin{abstract}
15 AT, IX-2, 45.
16 Al leer estos textos de los Principios es difícil evitar la embarazosa impresión de que este deajuste entre las definiciones de lo que es «propiamente» sustancia y las sustancias creadas -es decir, esta primera consecuencia de ese hilo creacionista que, articulándola, atraviesa la reflexión de Descartesparece exigir una cierta falta de precisión en la definición de algunos de los conceptos fundamentales que organizan toda teoría de la sustancia. Nos referimos a los conceptos de «propiedad», «atributo» y «modo». En los artículos finales de esta primera parte de los Principios, en efecto, parece deslizarse una sutil confusión por lo que se refiere a los términos o a las categorías mencionadas. Así, por ejemplo, el pensamiento y la extensión, atributos principales de la cosa pensante y de la cosa extensa respectivamente, deben ser concebidos «como la sustancia misma que piensa y que es extensa, es decir, como el alma y el cuerpo», y ello «porque [procediendo] de esta suerte los conocemos muy clara y muy distintamente» (art. 63). Pero lo que más llama la atención del lector atento es que esos mismos «atributos principales» puedan ser considerados, en aras de un conocimiento igualmente claro y distinto, «como los modos o las diferentes maneras que se encuentran en la sustancia» (art. 64). Un cono-
\end{abstract}


las cuales pueden ser conocidas ${ }^{17}$. «Propiedades», «atributos» o «modos» cuya existencia depende de esas sustancias mismas que dan a conocer $-\mathrm{y}$ es evidente que también, pero ni única ni directamente, de Dios-. El significado del término «sustancia», por tanto, es utilizado principalmente como criterio de distinción aplicable al ámbito total de la creación ${ }^{18}$, de modo que la operatividad del concepto se hace visible y pregnante, sobre todo, en el ámbito de lo finito y aludiendo a las modalidades de su existencia.

Nos convenceremos fácilmente de ello constatando que el movimiento discursivo de los Principios no ha partido de la definición de lo que es «sustancia» en sentido propio o eminente. En realidad, ha sido la economía de la exposición lo que ha hecho necesario introducir la definición que aparece en el artículo $51 \mathrm{y}$, con ella, la equivocidad. Y ha sido el peso específico del principio del creacionismo dentro del sistema lo que ha exigido la introducción de esta radical distinción entre, por una parte, el estatuto ontológico de la sustancia propiamente tal y, por otro, tomadas como en bloque, esas sustancias en sentido derivado que son las «sustancias intelectuales» y las «sustancias corporales». Ello explica que a continuación sea restablecida una cierta univocidad del término; univocidad que puede proponerse tan sólo, obviamente, a condición de no abandonar los límites que trazan la frontera del ámbito propio de esas extrañas sustancias que -no se sabe muy bien cómo, pues es imposible saberlo- son creadas:

Y la noción que tenemos así de la sustancia creada, se refiere de la misma manera a todas, es decir, tanto a aquellas que son inmateriales, como a aquellas que son materiales o corporales. 19

Una vez hecho este paréntesis acerca de la equivocidad del término en el artículo 51, Descartes puede cartografiar, recuperando el univocismo, la abigarrada variedad del mundo que nos ofrece la experiencia: puede distinguir atributos, propiedades, modos, etc., y establecer las maneras como nos dan a conocer unas sustancias que ya sabemos que son criaturas 20 . De las dos clases de equivocidad que la tradición aristotélico-escolástica reconoce -por un lado, entre la sustancia divina y la sustancia creada, y, por otro, entre la sustancia espiritual y la sustancia material-, nuestro autor mantiene la primera pero rechaza la segunda. El término «sustancia» o res no se aplica equívocamente a la res cogitans y a la res extensa, sino unívocamente. Ambos tipos de sustancia son igualados en este primer momento por el mero hecho de ser ambas criaturas.

cimiento «muy claro y muy distinto» parece permitirnos, y aún exigir, tomar lo que es atributo principal, e incluso lo que no son sino modos de las sustancias creadas, por esas sustancias mismas...

17 Cf . AT, IX-2, 47 citado más adelante.

18 Cf. J.-L. Marion, Sur la théologie blanche de Descartes, op. cit., p. 112.

19 AT, IX-2, 47. 
Sea como fuere, lo que nos interesa subrayar son las consecuencias fundamentales de esta permanencia de la reflexión propia de los Principios en el plano de lo creado, las implicaciones de la necesidad de pensar este plano según la lógica general de la equivocidad, y lo que va a exigir de la teoría esta recuperación -necesariamente restringida- de la univocidad. Todo ello entraña una modulación fundamental del criterio de la sustancialidad en sentido eminente - una laxitud en el momento de extraer las consecuencias de su definición-que se revelará esencial en el desarrollo de la teoría y que pondrá en marcha la construcción metafísica más sistemática del XVII; ésta se forjará como respuesta a las dificultades que suscitan el equivocismo cartesiano y sus implicaciones; es decir, se desarrollará como crítica ${ }^{21}$. En función de aquella modulación, la ontología cartesiana de la sustancia se dotará efectivamente de un contenido material, concreto. Pero lo hará de un modo intrínsecamente problemático; como consecuencia de esta equivocidad serán diluidas como de un plumazo aquellas propiedades de la sustancia que su definición en sentido propio parecería implicar necesariamente. Es evidente que las propiedades que califican a la noción de sustancia creada de ninguna manera pueden concordar con las deducibles de la inseidad y de la perseidad de la definición originaria: la existencia necesaria, la infinitud y la unicidad.

En primer lugar, si la definición de sustancia en sentido propio implica necesariamente la afirmación de la autosuficiencia o autonomía absoluta de su existencia, no puede predicarse lo mismo de las sustancias creadas; de ningún modo, es evidente, una sustancia creada puede bastarse a sí misma, en sentido absoluto, para existir. Afirmarlo equivaldría a una estricta contradicción en los términos. Una sustancia creada es una sustancia necesariamente finita. ${ }^{22}$ A partir de la sola definición de sustancia en sentido equívoco se hace imposible saber si una sustancia existe o no. Sólo en virtud de una remisión más o menos directa a la experiencia ${ }^{23}$, tomada ésta en un sentido muy amplio, se hace posible conocer y afirmar su existencia. ${ }^{24}$

20 Cf. AT, IX-2, 53-55.

21 Así es como deben leerse, en nuestra opinión, la primera parte de la Ética de Spinoza, o algunas obras fundamentales de Leibniz (la Monadología o el Discurso de metafísica) y Malebranche (en especial, los libros I y IV de la Recherche de la vérité).

22 Y de sustancias «finitas» habla el propio Descartes. Por ejemplo en la tercera meditación, en la que compara la realidad objetiva de nuestra idea de Dios con la realidad objetiva de las ideas que tenemos de las sustancias finitas: «[...] esta [idea] por la cual concibo a un Dios soberano, eterno, infinito, inmutable, omnisciente, omnipotente y creador universal de todas las cosas que son fuera de Él; esta idea, digo, contiene ciertamente en sí más realidad objetiva que aquellas [ideas] por las cuales las sustancias finitas me son representadas» (AT, IX-1, p. 32).

$23 \mathrm{Y}$ tal vez por ello pueda decirse que la célebre fórmula cartesiana a propósito de la existencia del cogito -cualquiera que sea la variante en que se formule: la del Discurso, la de las Meditaciones, la de los Principios - no puede ser tomada por una deducción, sino tan sólo por una constatación.

${ }^{24}$ Cf. AT, IX-2, 47: «Pero cuando se trata de saber si alguna de estas sustancias existe verdaderamente, es decir, si es en el presente en el mundo, no basta con que exista de esta manera para hacer que la 
Es decir, no es demostrable a priori; debe ser constatada. Pensar la existencia de las sustancias, según Descartes, es pensar su contingencia. Así pues, ni infinitud de las sustancias ni, por consiguiente, necesidad absoluta de su existencia. Además, una tercera consecuencia - estrictamente vinculada de nuevo, de forma directa, con el creacionismo cartesiano- parece imponerse con la misma fuerza que las anteriores. Si determinadas criaturas pueden ser llamadas «sustancias» porque precisan -aunque sea directa y únicamente- de un principio trascendente tanto para existir como para subsistir y perseverar en la existencia, ninguna contradicción habrá en reconocer una pluralidad de sustancias de igual atributo, aunque la sustancia propiamente tal no pueda sino ser única. Es lo que Descartes establece cuando, más adelante en los Principios, trata de la distinción real:

La [distinción] real se da propiamente entre dos o varias sustancias. Pues podemos concluir que dos sustancias son realmente distintas la una de la otra a partir de esto: de que podemos concebir clara y distintamente la una sin pensar en la otra. 25

El rendimiento final de este equivocismo que dirige la reflexión en los Principios es, así pues, triple: permite, primeramente, atribuir análogamente a ciertas criaturas - pero de forma muy mitigada- la autosuficiencia que propiamente pertenece en exclusiva a Dios excluyendo la necesidad de su existencia; conduce, en segundo lugar, a reconocer una pluralidad de sustancias que comparten un mismo atributo; $y$, finalmente, hace posible distinguir realmente sustancias de atributo distinto (por ejemplo alma y cuerpo) ${ }^{26}$. Pluralidad, por tanto, de sustancias formalmente idénticas. Pluralidad de sustancias que piensan y pluralidad de sustancias materiales o extensas ${ }^{27}$. Esto es, distinción real, simultáneamente, entre sustancias creadas de diferente y de idéntico atributo principal. Pluralidad y consideración de

percibamos; pues esto solo no nos descubre nada que excite algún conocimiento particular en nuestro pensamiento. Hace falta, además de esto, que tenga algunos atributos que podamos notar; y ninguno hay que no sea suficiente a este efecto, pues una de nuestras nociones comunes es que la nada no puede tener ningún atributo, ni propiedades, ni cualidades. Por ello, cuando encontramos alguno, podemos concluir con razón que es el atributo de alguna sustancia, y que esta sustancia existe».

25 AT, IX-2, 51.

26 Cf. Ibid.: «Igualmente, puesto que cada uno de nosotros percibe en sí mismo que piensa, y que puede, pensando, excluir de sí mismo o de su alma toda otra sustancia que piense o que sea extensa, podemos concluir también que cada uno de nosotros, así considerado, es realmente distinto de toda otra sustancia que piense, y de toda sustancia corporal».

27 Creemos posible hablar de una pluralidad de «sustancias materiales» a partir de los textos que estamos utilizando. Ahora bien, es innegable que la pluralidad de sustancias materiales plantea un grave problema del que Descartes es consciente. Problema que, por así decir, gravita en torno a toda su obra. En las Meditaciones, por ejemplo, no hablará de «sustancias materiales», sino del «cuerpo, tomado en general», que será «sustancia» (AT, IX-1, 10). El cuerpo humano estará formado y compuesto por una cierta «configuración de accidentes» (ibíd.). A partir de su diferencia respecto del alma será probada la inmortalidad de ésta. De tal problema nos ocupamos un poco más adelante. 
tales sustancias como sustancias en sentido derivado o equívoco que se hace posible, en definitiva, porque el principio de todo lo que es -Dios o la sustancia en sentido propio o eminente-, es un principio trascendente que lo crea todo en virtud de una potencia o voluntad absoluta.

Tales son los principios fundamentales, generales, de la teoría desarrollada en la primera parte de los Principios. Teoría, es importante insistir en ello, con la que nuestro autor separa radical, tajantemente, las dos esferas fundamentales de lo real - por un lado, Dios, sustancia en sentido propio, fundamento del ser de todo lo que es, y, por otro, sustancias en sentido equívoco, cosas cuya esencia y existencia es, en principio, absolutamente indigente-, y que se ofrece como intento por tematizar el espesor de lo creado, y su dependencia (casi) absoluta.

Ahora bien, no todas las sustancias pueden poseer un mismo estatuto ontológico; la teoría ha de ser completada. La fundamentación de su desigualdad vendrá del reconocimiento de un parecido, de la conceptualización de la relación que entre sí guardan Dios y ciertas sustancias creadas - pero ya no todas- como relación de semejanza, manteniendo siempre la coherencia con el principio creacionista. Ello hará preciso llevar más lejos aquella analogía que doblaba la equivocidad aplicada al término «sustancia» y que era como el primer motor de esta teoría; de lo que se tratará ahora será de conceptualizar una semejanza en sentido eminente. Así es como Descartes podrá pensar la creación como un orden estrictamente jerárquico, como cifra ordenada de la naturaleza de su creador: pensará radicalmente una distinción fundamental entre los dos tipos de sustancias creadas que admite. Pero no lo hará ya recurriendo sin más a la lógica del equivocismo. La reflexión se desarrollará, ganará en profundidad, afinando lo que nosotros llamaremos un uso «salvaje», exacerbado, de la analogía. Uso éste, por lo demás, muy característico de la metafísica que construye nuestro autor.

\section{Una analogía salvaje. Teoría del orden mundano}

La teoría cartesiana de la sustancia se completa con un análisis complejo del espesor real del mundo; funciona también como garantía de un orden estricto, jerárquico, en el interior mismo de la creación. Aunque, como hemos visto, en los Principios se recupera una cierta univocidad para pensar esta esfera, si nos acercamos a la reflexión desarrollada en las Meditaciones constatamos que aquí es sistematizado un cierto desnivel esencial entre los dos tipos de sustancias que la pueblan: las «sustancias pensantes» y las «sustancias materiales». Con ello no debe entenderse que estemos acusando al francés de incoherencia o de haber abandonado en los Principios sus posiciones previas; no todas las sustancias creadas poseen 
un mismo estatuto ontológico, lo que no impide que sea legítimo, siguiendo la lógica cartesiana, denominar a todas «sustancia» por igual, unívocamente. Nuestra tesis es que esta reproducción del mencionado desnivel ontológico - no ya entre Dios y las criaturas, sino dentro del plano de estas últimas- viene impuesta, una vez más, por el creacionismo o voluntarismo que determinan férreamente la reflexión de nuestro autor. El hecho de que dicho principio opere en el análisis de todos los estratos de la realidad, hace difícilmente cuestionable que constituya el más fundamental de entre los que determinan la forma específica de la metafísica de Descartes. Es su pregnancia en el interior de la esfera de la creación lo que le conduce a pensar la relación entre Dios y determinadas sustancias según una cierta relación de analogía. Pero según una relación de analogía, por así decir, «salvaje», fronteriza con la identificación estricta - en las Meditaciones se tematizará una «identidad formal»-, y no ya, como en la primera parte de los Principios, dictada en exclusiva por las implicaciones más generales, más abstractas, de la lógica de la equivocidad, las cuales garantizaban la legitimidad de una recuperación posterior del univocismo. Este uso «salvaje» dará su forma al espacio intelectual que se inaugura con la reflexión cartesiana y que es legado al siglo: el espacio construido sobre la teorización de la semejanza que presenta una facultad propia de determinadas sustancias creadas respecto de la potencia absoluta e indeterminada de Dios. La cifra de dicha semejanza estará, en efecto, en la voluntad o libre albedrío, propiedad exclusiva de un tipo de sustancias que, por el factum de su posesión, se hacen acreedoras de un estatuto ontológico totalmente especial. Aunque pueda decirse, cartesianamente, que son sustancias exactamente de la misma manera como lo son aquellas otras que carecen de libre albedrío...

De la centralidad de la distancia ontológica entre «sustancia intelectual» y «sustancia corporal» en esta metafísica, es un buen indicio la insistencia con que, ya desde la Carta a los decanos y doctores de la Sorbona con que prologa sus Meditaciones, vincula Descartes las razones que prueban la existencia de Dios con las que prueban que el alma humana difiere del cuerpo ${ }^{28}$. Ello permite atribuir a aquélla propiedades no sólo distintas de las que pueden atribuirse a éste, sino también contrarias; por ejemplo la unidad y la inmortalidad. Propiedades ambas que hacen del alma, frente al cuerpo humano concreto, una «sustancia pura», o una «pura sustancia» ${ }^{29}$ : unitaria, inmutable e inmortal por su propia naturaleza 30 .

28 AT, IX-1, 7-8. Cf. asimismo el final de la quinta parte del Discurso del método: «[...] cuando se sabe cuánto difieren [el alma humana y el de las bestias], se comprenden mucho mejor las razones que prueban que la nuestra es de una naturaleza enteramente independiente del cuerpo y, en consecuencia, que no está sujeta a morir con él; después, en tanto que no se ve otras causas que la destruyan, estamos naturalmente inclinados a juzgar a partir de ahí que es inmortal» (AT, VI, 59-60).

29 Es lo que afirma en su Abrégé des six Méditations suivantes (AT, IX-1, 10): «[...] el cuerpo, tomado en general, es una sustancia; por ello, también, no puede morir. Pero el cuerpo humano, en tanto 
Propiedades del alma, en definitiva, que la muestran como sustancia eminentemente análoga al principio creador de todas las cosas, esto es, a Dios. Y ello no sólo porque se pueda afirmar que la existencia del alma, o del cogito (antes incluso de conocer «bastante claramente» qué es en su concreción real esa alma), sea la primera «cosa que es cierta e indudable», algo así como una nueva palanca de Arquímedes 31 con la cual escapar de la duda metódica e hiperbólica. Ni tampoco porque tal vez sea posible afirmar que el cogito puede ser la causa de la realidad objetiva de todas aquellas de entre sus ideas que expresen una realidad que ego puedo contener «formal o eminentemente» 32 ; es decir, porque tal vez pueda ser la causa de las ideas «de las cosas corporales ${ }^{33}$, o de la idea misma de sustancia ${ }^{34}$. Ni siquiera porque pueda incluso ser la causa eminente de las ideas de extensión, figura, situación, etc ${ }^{35}$. No. El alma es concebida como una sustancia pura, o como una sustancia más análoga a Dios, porque cuando Descartes avance en el conocimiento de lo que es el alma, sus propiedades se mostrarán, a diferencia de las del cuerpo, como más análogas a ciertas propiedades de Dios - a ciertas propiedades divinas de cuya manera de ser conceptualizadas depende la forma y el desarrollo de toda su metafísica-. La relación entre las «sustancias intelectuales» creadas y Dios debe ser pensada, en consecuencia, como muy única y muy directa. El movimiento discursivo con el que se establece en las Meditaciones la unicidad de esta relación es ciertamente complejo.

Arranca con la primera prueba de la existencia de Dios propuesta en la tercera meditación. Su hilo argumental consiste en la inspección de las ideas que se ofrecen al cogito para comprobar si hay alguna que verdaderamente remita a algo que le sea exterior o no. Es decir, para comprobar si aquél dispone de alguna idea que no pueda ser considerada, por expresarnos como lo hace el mismo Descartes, como una «pura producción o ficción de mi ingenio» 36 . Dicha inspección, como es bien

que difiere de los demás cuerpos, no sólo está compuesto y formado por una cierta configuración de miembros, y por otros accidentes semejantes; el alma humana, por el contrario, no está compuesta así por accidente alguno, sino que es una pura sustancia».

30 «Pues aun cuando todos sus accidentes cambian, por ejemplo, aun cuando conciba ciertas cosas, las quiera, sienta otras, etc., no obstante es siempre la misma alma. Mientras que el cuerpo humano no es ya el mismo con que sólo sea cambiada la figura de algunas de sus partes. De donde se sigue que el cuerpo humano puede perecer fácilmente, pero que el ingenio o alma del hombre (cosas éstas que yo no distingo) es inmortal por su naturaleza» (ibíd.). La meditación sexta retomará todas estas indicaciones preliminares al desarrollo de las Meditaciones y concluirá la distinción real entre cuerpo y alma estableciendo una diferencia de estatuto ontológico entre ambas sustancias: «[...] hay una gran diferencia entre el alma y el cuerpo: el cuerpo, por su naturaleza, siempre es divisible, y el alma humana es enteramente indivisible...» (AT, IX-1, p. 68).

31 Cf. el inicio de la segunda meditación (AT, IX-1, 19).

32 Cf. AT, IX-1, 33.

33 «Y en cuanto a aquello que concierne a las ideas de las cosas corporales, no reconozco nada tan grande y excelente que no me parezca que puede proceder de mí mismo» (AT, IX, 34).

34 AT, IX-1, 35.

35 AT, IX-1, 36.

36 AT, IX-1, 41. 
sabido, resulta en la constatación de que la idea de Dios, de una sustancia infinita, no puede tener su origen «en mí»; así llegamos a la conclusión de que Dios existe 37 . Pero lo esencial es que dicha inspección ha mostrado la anterioridad lógica de la noción de infinito y que a partir de aquí puede encontrarse una vía para demostrar dos principios fundamentales: que Dios es causa del cogito en cuanto que éste contiene su idea -en cuanto que se sabe contingente y finito, pues se sabe tal por contener «de alguna manera primeramente» la idea de infinito ${ }^{38}$; y, en segundo lugar, que el hombre ocupa una posición en todos los sentidos excepcional dentro de la creación. Será una reflexión en torno a la presencia de esta idea de infinito en el fuero interno de una sustancia finita lo que permita medir el espesor ontológico del mundo y dar unos contornos claros al espacio teórico que inaugura Descartes.

La constatación de esta presencia conduce al establecimiento de una analogía entre el alma y Dios más inmediata que la que puede establecerse entre Dios y las sustancias no «intelectuales» que la sustancia infinita crea. El francés cierra esta meditación desarrollando la proposición según la cual

[...] ya no queda por decir sino que, como la idea de mí mismo, ella [la idea de Dios, la idea de un ser soberanamente perfecto] ha nacido y ha sido producida conmigo desde que yo he sido creado. 39

Con dicha proposición se establece con toda claridad una igualación más o menos relativa entre la conciencia y la idea de Dios. La metáfora utilizada no deja lugar a dudas; la idea de Dios contenida en el cogito es la marca de mi creador, marca que se confunde con la obra misma, esto es, con el fuero interno mismo:

Y ciertamente no debe resultarnos extraño que Dios, creándome, haya puesto en mí esta idea para que sea como la marca del obrero impresa sobre su obra; y tampoco es necesario que esta marca sea algo diferente de esta misma obra. Pues sólo porque Dios me ha creado, es muy creíble que de alguna manera me ha producido a su imagen y semejanza, y que concibo esta semejanza (en la que se halla contenida la idea de Dios) mediante la misma facultad por la que me concibo a mí mismo.40

37 Sobre el alcance de esta prueba de la existencia de Dios, y su vinculación con el creacionismo divino, cf. H. Gouhier, La pensée métaphysique de Descartes, París, Vrin, 1999 (1962), pp. 179-180 y 186194.

38 AT, IX-1, 36: «[...] veo manifiestamente que hay más realidad en la sustancia infinita que en la sustancia finita, y, por lo tanto, que de alguna manera tengo primeramente en mí la noción de infinito que la de finito; es decir, la de Dios que la de mí mismo. Pues, ¿cómo sería posible que yo pudiese conocer que dudo y que deseo, es decir, que me falta algo y que no soy enteramente perfecto, si no tuviera en mí ninguna idea de un ser más perfecto que el mío, en comparación con el cual conocería los defectos de mi naturaleza?».

39 AT, IX-1, 41.

40 Ibid. 
La semejanza se establece primeramente entre Dios y todas sus criaturas; el axioma según el cual el efecto se asemeja a su causa presupone en el caso de la creación de las sustancias finitas, como ha señalado Henri Gouhier, que dicha creación sea ex nihilo; sólo en virtud de ese presupuesto se hace tal axioma imperativo ${ }^{41}$. Entre toda sustancia finita y Dios se establece una cierta relación de analogía, aunque tan sólo sea en la medida en que Dios y toda sustancia creada pueden recibir equívocamente la misma denominación, o porque la existencia de las sustancias finitas no precisa del concurso de otras sustancias creadas. Tal es la tesis de los Principios, al menos hasta donde nosotros la hemos seguido.

Pero en el caso del hombre, de las «sustancias intelectuales», algo se añade, reforzándola, a esta semejanza, llamémosla así, primaria. Entre la «sustancia intelectual»y Dios dicha relación ha sido llevada un poco más lejos en las Meditaciones. Entre el cogito y Dios se puede reconocer una semejanza que va más allá del criterio de la autonomía ontológica. Hay un contenido del cogito que nos hace semejantes a Dios -su idea, «marca» de nuestro creador- y que, al mismo tiempo, hace posible visualizar esa semejanza. Además, la conciencia, la facultad en virtud de la cual «yo me concibo a mí mismo» y que es inseparable de esa potencia de visualización, no tiene por qué ser algo distinto - dice Descartes- de esa idea que es marca de su creador y que ego no he podido generar. La idea de una sustancia infinita, idea contenida en toda conciencia finita, sirve, pues, para demostrar el esencial carácter de criatura del cogito mismo, y también, puesto que es indudable que el cogito existe, la necesaria existencia de su creador. O sea, de Dios:

[...] Dios existe, pues aunque la idea de la sustancia está en mí [...], no tendría yo, sin embargo, la idea de una sustancia infinita, yo que soy finito, si no hubiese sido puesta en mí por alguna sustancia que fuese verdaderamente infinita. 42

Sin embargo, éste es sólo el primer paso del complejo movimiento discursivo cartesiano. Sólo somos en cierto modo semejantes a Dios. La conciencia se muestra a sí misma como finita; nos permite reconocernos como semejantes a una sustancia que posee en acto e infinitamente las perfecciones que definen a esta facultad del cogito. Dicho reconocimiento significa en este primer estadio de la argumentación que la infinitud y la actualidad a las que nuestro fuero interno tan sólo puede aspirar marcan claramente la diferencia entre éste y Dios. Semejanza, pues, como distancia; semejanza, por el momento, en sentido relativamente negativo. La

41 Cf. La pensée métaphysique de Descartes, op. cit., p. 195: «[...] l'axiome [el efecto se asemeja a su causa] n'est impératif que là où il y a création au sens plein du terme, création ex nihilo. Si Dieu, être et substance, crée de rien quelque chose qui soit de l'être et de la substance, la relation ainsi posée inclut une certain ressemblance...».

42 AT, IX-1, 35-36. 
conciencia halla en sí misma ciertas perfecciones «indefinidamente y solamente en potencia» que, en acto y elevadas al infinito, pertenecen a Dios ${ }^{43}$.

No obstante, la «sustancia intelectual finita» encuentra en sí una facultad que en cierto modo neutraliza esta distancia entre finito e infinito; facultad que se revelará «formalmente» idéntica en ella y en Dios: la hallará en sí no ya, como el entendimiento, «indefinidamente y solamente en potencia», sino que comprenderá que dispone de ella «actualmente e infinitamente». Es la presencia de esta otra facultad lo que hace en verdad del alma, definitivamente, una sustancia de mayor rango ontológico que cualquier otra sustancia finita; es la que expresa una semejanza ya del todo positiva entre ella y Dios. Tal facultad no es sino la voluntad o libre albedrío, igualmente infinita en el hombre y en Dios y, por ello, formalmente -pero no materialmente- idéntica en ambos. De esta manera, el voluntarismo creacionista, verdadero eje vertebrador de la metafísica de Descartes, se convierte en principio que no sólo atraviesa, explicando su distinción, su separación tajante, todos los planos de la realidad -el del fundamento y el de lo fundamentado o creado-, sino que también ordena jerárquicamente la variedad del mundo, la variedad de tipos de sustancia, y sus consiguientes propiedades, atributos y modos, de una forma que se quiere definitiva. El orden y la variedad de la creación será transcrito también como orden y variedad -esto es, como teoría- de la libertad de la voluntad de esas sustancias creadas que se van a revelar como eminente, «salvajemente» análogas a su creador. Será transcrito como teoría de los usos y las funciones del libre albedrío, y también, por supuesto, como doctrina acerca del especial estatuto que éste otorga inmediatamente a quienes son en exclusiva sus poseedores. Para desarrollar esta hipótesis debemos volver atrás y retrotraernos por un instante al comienzo de la tercera meditación para pasar, acto seguido, a la cuarta.

La meditación tercera se abre con el resumen de lo que hasta el momento se sabe verdaderamente que es el alma o ego que sirve de soporte al cogito -una cosa que piensa ${ }^{44}$ - para dividir a continuación sus pensamientos en «géneros» y así establecer en cuáles hay propiamente verdad o error. Pues bien, error, propiamente, no lo hay sino en los juicios, en virtud de que en su formación concurren dos facultades inconmensurables entre sí. Lo que nos interesa a nosotros, obviamente, no es la teoría cartesiana del juicio en su detalle, sino lo que nuestro autor afirma como pro-

\footnotetext{
43 Cf. AT, IX-1, 41: «[...] cuando reflexiono sobre mí mismo, no solamente conozco que soy una cosa imperfecta, incompleta y dependiente de otro, que tiende y que aspira sin cesar a algo mejor y más grande de lo que yo soy, sino que también conozco, al mismo tiempo, que aquel de quien dependo posee en sí todas estas grandes cosas a las que yo aspiro y cuyas ideas hallo en mí, no indefinidamente y solamente en potencia, sino que disfruta de ellas en efecto, actual e infinitamente, y, así, que es Dios».

44 «[...] es decir, que duda, que afirma, que niega, que conoce unas pocas cosas, que ignora muchas otras, que ama, que odia, que quiere, que no quiere, que también imagina y que siente» (AT, IX-1, 27).
} 
legómeno a su construcción: la distinción de voluntad y entendimiento. No podemos igualarnos a Dios en función de éste; nuestro entendimiento nunca puede llegar a ser actualmente infinito. 45 La misma distancia que separa lo finito de lo infinito es la que separa a mi entendimiento del divino. Sin embargo, no puede decirse lo mismo de la otra facultad que el alma halla en sí misma...

En la cuarta de las Meditaciones metafisicas, en el momento mismo en que se reafirma la tesis según la cual el error procede del concurso de entendimiento y voluntad, Descartes señala una importante diferencia que califica a ambas facultades: la una es finita y muy limitada; la otra, más perfecta y extensa:

No puedo tampoco quejarme de que Dios no me haya dado un libre arbitrio, o una voluntad lo suficientemente amplia y perfecta, porque, en efecto, yo la experimento tan vaga y tan extensa que no está encerrada en ningún límite. Y lo que me parece muy notable a este propósito es que, de todas las demás cosas que hay en mí, ninguna hay que sea tan perfecta y tan extensa como para que no pueda reconocer que podría ser más grande y más perfecta 46

La diferencia es crucial. El entendimiento o «facultad de concebir que hallo en mí» es algo limitado. Junto con la representación de la forma de nuestro propio entendimiento - sea cual sea la extensión de su contenido real, la cual, de cualquier manera, nunca puede ser infinita-, se presenta inmediatamente la de otro más amplio, «e incluso infinito», que no podemos sino atribuir a Dios. La voluntad, por el contrario, no puede sino representarse como «tan perfecta y tan extensa» que sólo puede ser visualizada como unitaria porque infinita -porque, como se dice en el texto que acabamos de citar, «no está encerrada en ningún límite»-:

La voluntad, dado que no consiste sino en una sola cosa, y al ser como indivisible, parece poseer una naturaleza tal que no se podría suprimir nada de ella sin destruirla por completo 47

Lo fundamental aquí es que la voluntad va a revelarse a continuación como potencia indivisible y absoluta; como potencia que va a ser definida literalmente como potencia de elección o libre albedrío. Es decir, como capacidad de determi-

\footnotetext{
45 Cf. AT, IX-1, 45: «[...] si considero la facultad de concebir que hay en mí, hallo que es de una extensión muy pequeña y grandemente limitada, y, a la vez, me represento la idea de otra facultad mucho más amplia, e incluso infinita; y por el solo hecho de que me puedo representar su idea, conozco sin dificultad que pertenece a la naturaleza de Dios [...] aunque mi conocimiento aumentase cada vez más. No obstante, no dejo de concebir que no podría ser actualmente infinito, puesto que nunca alcanzaría un punto tan alto de perfección que no fuese capaz de aumentar algo más».

46 AT, IX-1, 45.

47 AT, IX-1, 48.
} 
nación espontánea, susceptible de sustraerse a toda determinación exterior a ella misma. Potencia o capacidad, por tanto, de ruptura respecto de cualquier sistema de necesidad. Ésta es su forma propia, aquello en virtud de lo cual puede afirmarse sin tapujos su identidad con la voluntad - con la potencia- divina. Sin ser, como la voluntad de Dios, creadora de cosas, instauradora de órdenes nuevos, la voluntad del hombre es semejante a aquélla en el sentido de que puede determinarse por sí y desde sí misma, en una dirección u otra, sin que sea necesariamente determinada por nada exterior a su forma misma. Entendimiento y voluntad o libre albedrío son, por tanto, dos facultades distintas, exteriores la una a la otra, y, sobre todo, inconmensurables. Mientras que el primero es limitado porque carece de gran cantidad de ideas y porque puede no concebir ni clara ni distintamente aquellas de las que dispone -es decir, porque carece de todas las ideas que conforman el entendimiento divino y porque no concibe todas las que tiene como Dios las concibe, como el entendimiento mismo debería concebirlas si fuese perfecto-, la segunda es ilimitada porque incluso en el hipotético caso de que el entendimiento del hombre fuese infinito, no precisaría de una «forma» distinta de la que actualmente posee aun viéndose, como se ve, acompañada de un entendimiento finito. Ésta es la razón por la cual voluntad humana y voluntad divina van a ser consideradas de inmediato como formalmente idénticas.

En efecto, es esta distinción de forma entre las dos facultades constituivas del cogito lo que lleva a Descartes a reconocer en la voluntad, por segunda vez, y fundacional, definitiva, «principalmente», la verdadera cifra de la semejanza del hombre con Dios:

Nada hay, aparte de la sola voluntad, que pueda experimentar en mí ser tan grande que no conciba la idea de ninguna otra más amplia y más extensa, de suerte que es ella principalmente lo que me hace conocer que porto la imagen y la semejanza de Dios. Pues, aunque sea incomparablemente más grande en Dios que en mí -sea en razón del conocimiento y la potencia que, al hallarse en ella juntas, la hacen más firme y eficaz, sea en razón del objeto, en tanto que se dirige y extiende a infinitamente más cosas-, no me parece sin embargo más grande si la considero formal y precisamente en sí misma 48 (subrayados nuestros).

A pesar, pues, de las diferencias entre «mi» voluntad y la divina -diferencias que afectan a sus contenidos y funciones: a su potencia para crear cosas e instaurar verdades-, las dos son en cierto sentido idénticas. La voluntad, pues, es cifra exacta y completa de semejanza con Dios. Su representación no se limita ya a señalar un mero parecido entre el cogito y una de sus ideas; en este momento de la reflexión, la voluntad misma -su forma-, y no un mero contenido de la conciencia, pasa a ser

48 AT, IX-1, 45-46. 
señal inequívoca de dicha semejanza. Lo que se reconoce es, pues, una estricta identidad entre la forma de una facultad real del alma humana y la forma real de uno de los principales atributos de la naturaleza de Dios: su potencia. El hombre, definitivamente, no puede en modo alguno ser considerado como una sustancia creada más al lado del resto de sustancias y cosas creadas por Dios.

El desarrollo de las consecuencias que se deducen de este principio será lo que dote a la metafísica cartesiana de una especificidad cuya forma determinará el espacio conceptual de la Modernidad. En efecto, ¿qué significa, profundamente, esta manera de pensar el especial estatuto ontológico de las «sustancias pensantes»? ¿Qué significa que la voluntad sea lo que hace de la res cogitans un principio en cierto modo idéntico al principio de todas las cosas, algo -al igual que éste- no sometido inapelablemente a ningún tipo de necesidad, racional o natural; algo, dicho brevemente, que consiste en una potencia irreductible que puede ser definida como indiferencia, que puede situarse más allá incluso de las ideas claras y distintas que le ofrece o puede ofrecerle el entendimiento 49 ?

En primer lugar, significa el establecimiento de un fundamento a partir del cual construir una teoría compleja de la libertad y de la moral. La voluntad es pensada como la condición, como la raíz de la libertad del hombre precisamente porque es conceptualizada como potencia incondicionada ${ }^{50}$, como capacidad de suspensión de las leyes de la necesidad racional. Esto es, como capacidad de sustracción respecto de las determinaciones o indicaciones del entendimiento; como facultad capaz de seleccionar de entre los diversos tipos de ideas contenidas en aquél y escoger en virtud de cuáles determinarse: de ideas claras y distintas, de ideas confusas, o no determinarse en absoluto y detener así su tendencia espontánea a la emisión de juicios. Puede determinarse a no determinarse positivamente. La voluntad puede desvincularse incluso de la evidencia, como ha pretendido poner de manifiesto el propio Descartes al haber afirmado que ha suspendido su propio juicio a propósito de las verdades de la matemática mediante la ficción metodológica del «genio maligno». Voluntad humana, por tanto, y dado que es formalmente idéntica a la de Dios, como principio, en este sentido, absoluto.

\footnotetext{
49 Tesis ésta que se desprende muy claramente de la teoría acerca de la creación divina de las verdades eternas tal como la expone Descartes en su correspondencia con Marin Mersenne de la primavera del año 30: las verdades eternas son creadas, instituidas por Dios en virtud de un acto absoluto de su voluntad; ésta, por consiguiente, es anterior, se halla más allá, de la racionalidad misma. Puesto que lo crea todo, incluida la verdad, la voluntad divina no puede ser determinada por nada que no sea ella misma. Cf. AT, I, 135-154.

50 Cf. J.-M. Beyssade, La philosophie première de Descartes. Le temps et la cohérence de la métaphysique, París, Flammarion, 1979, pp. 185ss., y É. Boutroux, De veritatibus aeternis apud Cartesium (tesis latina), traducción francesa de G. Canguilhem, Des vérités éternelles chez Descartes, París, Vrin, 1985 (1927), p. 121.
} 
No obstante, tal vez pueda parecer extraño o paradójico que la «principal marca» de la semejanza del hombre con Dios sea una facultad a cuyo uso puede ser atribuida, en determinados casos, la formación de juicios falsos, del engaño y también, paralelamente, del pecado. La voluntad, acabamos de decir, es la verdadera raíz de la libertad; esto es, de la moral. Pues bien, es la función que esta raíz, posibilidad de la moral, desempeña en la metafísica cartesiana lo que va a permitir un establecimiento definitivo de las diferencias de estatuto ontológico que ordenan el interior del ámbito de la creación.

Poco antes de concluir esta meditación cuarta, Descartes hace una afirmación que nos muestra el camino para salir de la dificultad en que nos pone la constatación de que la voluntad es también la fuente del error y del mal:

[...] hay de alguna manera más perfección en mi naturaleza por el hecho de que puedo formarlos [los juicios en los que me engaño] que si no pudiera formarlos. ${ }^{51}$

La posibilidad del error -la posibilidad incluso de no formar deliberadamente un juicio conforme a una verdad claramente conocida- es signo de perfección. Efectivamente, la idea según la cual el libre albedrío testimonia claramente de cierta perfección en el hombre se desarrolla en la escritura cartesiana al hilo de la presunción de que la capacidad de detener la tendencia inmediata y espontánea de la voluntad a emitir juicios no se agota en el caso en que ésta espera a que el entendimiento disponga de ideas claras y distintas para poder conformarse a ellas. No es únicamente la mayor o menor claridad y distinción de las ideas lo que impele a la voluntad a detener ese impulso inmediato; se pueden emitir juicios falsos aun a sabiendas de que lo son. Descartes formula acabadamente esta idea en carta latina dirigida al padre Mesland en febrero de 1645:

[...] cuando una razón muy evidente nos lleva a un lado, aunque, moralmente hablando, apenas podemos seguir el partido contrario, absolutamente hablando, no obstante, podemos hacerlo. Pues siempre nos es posible retener nuestra persecución de un bien claramente conocido, o la admisión de una verdad evidente, supuesto que pensemos que es un bien afirmar con ello nuestro libre arbitrio. ${ }^{52}$

Siempre tenemos reservada la posibilidad de usar nuestro albedrío en sentido absoluto; utilización ésta que va a revelarse, más allá de toda duda razonable, como el punto máximo, fundamental, de aproximación de la voluntad del hombre a la de Dios. Los presupuestos de la doctrina cartesiana de la libertad quedan así definidos en el momento en que la facultad de determinación propia de la voluntad adquiere

\footnotetext{
51 AT, IX-1, 48.

52 Carta al padre Mesland del 9 de febrero de 1645 (AT, IV, 173).
} 
en la reflexión del francés un grado de independencia casi incondicionado respecto del entendimiento y de la propensión que éste produce en la voluntad 53 .

La conclusión general de todo ello tendrá una importancia decisiva, máxima, pues terminará de dar un fundamento sólido a la ordenación propuesta por Descartes en el ámbito de las sustancias creadas sin necesidad de abandonar ese principio creacionista que vertebra su metafísica toda. En efecto, el libre albedrío o voluntad convierte al hombre, en virtud de su semejanza con un Dios que es definido esencialmente como omnipotencia, en una excepción respecto del resto de la creación, en algo que escapa a las leyes que determinan al resto de cosas y de sustancias del mundo. Resto de cosas, de sustancias, incluso de verdades eternas, cuyo ser depende -al igual que el del hombre- de un acto absoluto de la voluntad divina, pero cuyas acciones y pasiones - a diferencia de la vida intelectual y moral del hombre, pues la voluntad de éste es igualmente absoluta en su forma que la de Diosestán estrictamente determinadas por una causalidad de carácter mecánico absolutamente predeterminada; es decir, por una legalidad por completo necesaria. Para terminar de rastrear la fundamentación de esta doctrina, se hace preciso abandonar las Meditaciones y volver sobre la primera parte de los Principios de la Filosofía.

En ella, la perfección del hombre es asignada en exclusiva, efectivamente, no a su entendimento, sino a su voluntad. El título del artículo 37 es muy significativo al respecto: «Que la perfección del hombre está en tener un libre arbitrio, y que éste es lo que le hace digno de alabanza o de culpa». 54 He aquí, definitivamente, el sentido en que la posibilidad de errar es signo de perfección. En virtud de esta posibilidad puede ser el hombre merecedor de alabanzas - cuando su voluntad se limita a afirmar representaciones o ideas claras y distintas- o de condenas -cuando afirma ideas confusas-:

[...] al ser la voluntad por su naturaleza muy extensa, nos es una ventaja muy grande poder obrar por medio de ella, es decir, libremente, de suerte que seamos de tal modo los dueños de nuestras acciones que seamos dignos de alabanza cuando las conducimos bien. 55

Es la forma de la voluntad, así pues, lo que revela al hombre como única criatura responsable de sus actos, como única criatura absolutamente dueña de lo que hace, lo cual le sitúa en una dimensión ontológica indiscutiblemente superior a la que corresponde al resto de sustancias creadas, a la(s) sustancia(s) creada(s) exten$\mathrm{sa}(\mathrm{s})$; en una dimensión, la única, en la que la moral puede cobrar un sentido claro.

\footnotetext{
53 Cf. J.-M. Beyssade, La philosophie première de Descartes, op. cit., p. 177.

54 AT, IX-2, 40.

55 Ibíd.
} 
De esta manera, y como no podría ser de otro modo, la reflexión acerca de la voluntad y el mérito o la culpa del hombre se ve acompañada en este mismo artículo de una comparación con aquello que carece de voluntad, con aquello que, siendo igualmente criatura, no es «sustancia intelectual»:

Pues así como no damos a las máquinas que vemos moverse de muchas y diversas maneras - de tantas como podríamos desear-alabanzas que se refieran verdaderamente a ellas, porque estas máquinas no representan ninguna acción que no deban hacer por medio de sus resortes, sino que se las damos al obrero que las ha hecho, porque ha tenido el poder y la voluntad de componerlas con tanto artificio, igualmente se nos debe atribuir algo más por el hecho de que elegimos lo que es verdadero, cuando lo distinguimos de lo falso, por una determinación de nuestra voluntad, que si fuésemos determinados y constreñidos a ello por algo extraño. 56

Es importante señalar que la comparación que se establece en este pasaje no sólo alude a las cosas que son extensas o a los artificios creados por el hombre. $\mathrm{O}$, más precisamente, que el texto no alude necesariamente a la(s) sustancia(s) exten$\mathrm{sa}(\mathrm{s})$ en general, sino que podría referirse, aunque no sea explícito al respecto, al cuerpo humano, máquina de igual estatuto que el resto de máquinas, que el resto de cosas extensas, a pesar de que pueda superar a todas en función de su grado de complejidad -el cual, en cualquier caso, no modificaría un ápice su estatuto ontológico-. La parte final del pasaje que acabamos de citar no deja lugar a la duda. Por el hecho de poseer un libre albedrío se debe atribuir algo más al alma, al ego del cogito, a aquello que ya puede ser considerado como verdadero ser del hombre. O, dicho a la inversa, es la carencia de voluntad lo que impone al resto de la creación un límite del todo infranqueable: la sitúa más acá de la virtud, más acá del bien y del mal. La condena a un tipo de determinación que en nada depende de ella misma. Nuestro estatuto ontológico queda por ello elevado un peldaño, y un peldaño decisivo, por encima del que corresponde al resto de sustancias creadas - a nuestro cuerpo-, o al resto de criaturas sin más y en general.

La correspondencia de Descartes con Cristina de Suecia - en la cual, junto con la que nuestro autor mantiene con Chanut y con Isabel de Bohemia, se esboza una moral y una política al hilo de una reflexión sobre la vinculación de cuerpo y alma 57 - es definitiva al respecto. En carta del 20 de noviembre de 1647, el centro

\footnotetext{
56 Ibid.

57 La bibliografía al respecto es prácticamente infinita. Destacamos algunos trabajos insoslayables: Antonio Negri, Descartes político o de la razonable ideología, Madrid, Akal, 2008 (1966); Pierre Guenancia, Descartes et l'ordre politique, París, P.U.F., 1986; Denis Kambouchner, Descartes et la philosophie morale, París, Hermann, 2008. Por lo demás, nos permitimos dar la referencia de un estudio muy reciente y en muchos aspectos magistral: Delphine Kolesnik-Antoine, Descartes. Une politique des passions, París, PUF, 2011.
} 
de la atención filosófica de nuestro autor lo ocupa ya del todo, explícitamente, la moral. La virtud, escribe, no consiste sino

[...] en la resolución y el vigor con los que nos inclinamos a hacer las cosas que creemos ser buenas, supuesto que este vigor no provenga de la obstinación, sino de que sabemos que las hemos examinado tanto como somos moralmente capaces de hacerlo. ${ }^{58}$

La fuente de la virtud es localizada, así, en una voluntad determinada tras un largo y exhaustivo trabajo de inspección y examen de las ideas que le ofrece el entendimiento. Voluntad cuyo uso determina el valor o el bien intrínseco de quien lo usa y, con ello, la posibilidad de la alabanza. Sólo del libre albedrío y de su uso depende la obtención de recompensas o de castigos; sólo de la voluntad y de su uso depende el que pueda atribuirse alguna virtud a quien la posee y la utiliza ${ }^{59}$. Y ello, como se subraya al final de esta misma carta -insistiendo en una idea que no ha dejado de acompañar a Descartes a lo largo de toda su biografía intelectual-, porque el libre arbitrio es el punto máximo de nuestra semejanza con el principio de cuya voluntad depende tanto la esencia como la existencia de todo lo que es y, por tanto, también las nuestras. Punto máximo de semejanza que es expresado ahora, de manera del todo explícita, como prácticamente una identidad. Por consiguiente, como algo fundamental:

[...] el libre arbitrio es de suyo la cosa más noble que puede haber en nosotros, y tanto más cuanto que nos hace de algún modo idénticos a Dios y parece eximirnos de estarle sometidos, $\mathrm{y}$, en consecuencia, su buen uso es el mayor de nuestros bienes, es también lo más propiamente nuestro y lo que más nos importa, de donde se sigue que sólo de él pueden proceder nuestros mayores contentos 60 (cursivas nuestras).

La voluntad - la cosa, literalmente, más noble, la más propiamente nuestra, la que hace posible aquello que más nos importa- nos hace de algún modo, por tanto, idénticos a Dios; esto es, fundamentalmente distintos al resto de sustancias, pues sólo en virtud de ella podemos igualarnos a Dios en el sentido de que podemos sustraernos a todo tipo de determinación externa...

En el resto de cartas que compone esta correspondencia -y en Las pasiones del $a l m a$ - el francés desarrollará una moral mucho más compleja que la expuesta como provisional en su Discurso del método, y dará indicaciones precisas, aunque no

\footnotetext{
58 AT, V, 83-84.

59 Cf. AT, V, 84: «Todos los demás bienes sólo merecen ser estimados, pero no honrados o alabados, en tanto que se presupone que han sido adquiridos u obtenidos de Dios por el uso del libre arbitrio. Pues el honor y la alabanza son una especie de recompensa, y nada hay, si no es aquello que depende de la voluntad, que pueda ser recompensado o castigado».

60 AT, V, 85.
} 
siempre explícitas, acerca de cómo deducir de ella, y de la antropología que supone, una política coherente con sus principios. No es éste el lugar para que nos ocupemos de ello; ha llegado para nosotros el momento de recapitular.

$* * *$

A pesar de haber recuperado en la primera parte de los Principios la univocidad, y de haberla introducido dentro del ámbito de las sustancias creadas, Descartes trata de fundamentar un desnivel ontológico irrebasable entre ellas en virtud del mayor grado de semejanza que presentan las «sustancias intelectuales» con Dios. Su metafísica parece admitir simultáneamente, así, una equivocidad entre dos términos -Dios, por un lado, y, por otro, las sustancias creadas tomadas en su conjunto-, para, en un segundo momento, conceptualizar la complejidad de lo creado recurriendo a la lógica de la analogía. Y a una lógica de la analogía que es exacerbada hasta el punto de desembocar en la tematización de una supuesta «identidad formal» entre la voluntad absoluta de Dios y la del hombre. Con ello quedan definitivamente fundamentadas las diferencias de estatuto ontológico entre los tres tipos de sustancias que constituyen los tres pilares fundamentales de su reflexión: sustancia infinita o Dios - principio creador de todo lo que es-, sustancias intelectuales -creadas, pero formalmente idénticas, sólo en función de su voluntad, al primer principio-, y, finalmente, sustancia(s) extensa(s) -creada(s) igualmente, pero sometidas a una legalidad que en nada depende de ellas, a una necesidad de la que de ninguna manera pueden sustraerse-. Las segundas, y sólo ellas dentro de la esfera de la creación, pueden suspender la forma de esa necesidad que determina legalmente, gobernándolo, el comportamiento del resto de las criaturas. La conceptualización que Descartes desarrolla a propósito de la voluntad como potencia absoluta de determinación, vinculada a su esfuerzo de redefinición de la noción tradicional de sustancia -a su disperso esfuerzo por construir una teoría a partir de un concepto perfectamente clásico-, es lo que termina de trazar esa suerte de cartografía de la variedad de la creación y de su estricto orden jerárquico en que consiste en buena parte su metafísica. Dicha conceptualización, en definitiva, es lo que galvaniza, lo que termina de dar un sentido propio, a la metafísica de nuestro autor y a los conceptos con que teje su trama.

En virtud de esa especial semejanza, en virtud de ese uso «salvaje» de la analogía, el hombre se revelará, si se nos permite utilizar una vieja expresión spinozana, como un imperio dentro de otro imperio, como una suerte de dios menor condenado a existir rodeado de cosas -y unido a cosas: su cuerpo- de menor rango ontológico que el suyo. Rodeado, en definitiva, de cosas que quizás se le asemejen menos de lo que él se asemeja a Dios. Tal será una de las concepciones -y no de las menos 
importantes- responsables de la forma general de la metafísica y la antropología del XVII61; es decir, del espacio teórico de la primera Modernidad. El horizonte intelectual que Descartes organiza rechazará por su propia naturaleza, en virtud de los principios que vertebran su estructura misma, todo conato de puesta en cuestión de la libertad de la voluntad.

Ahora bien, el creacionismo, y el consiguiente equivocismo unido al uso de la lógica de la analogía que aquí hemos rastreado, conducirán muy decisivamente a una serie de problemas que de inmediato va a ser señalada en la reflexión contemporánea e inmediatamente posterior a la cartesiana a propósito del concepto en torno al cual va a gravitar efectivamente la metafísica del siglo: el concepto de potencia. En la concepción del francés, ésta siempre es pensada como capacidad de ruptura, de sustracción a las leyes -a los sistemas- de la necesidad: la potencia de Dios es lo que instaura esos sistemas, esa necesidad, quedando por ello situada más allá de la verdad, de la racionalidad; y la potencia del hombre consiste fundamentalmente en su capacidad de determinación en función de la forma misma de su voluntad, al margen de los contenidos que puede ofrecerle el entendimiento. No otra es la razón por la que la metafísica cartesiana avanza demarcando zonas fundamentales de lo real que se muestran como esencialmente inasequibles para la razón finita del hombre: ésta nada tiene que decir ahí donde no hay causas eficientes asignables. La metafísica de Descartes, dicho de otro modo, inaugura una senda muy problemática, inagotable fuente de polémicas y discusiones a lo largo de la toda la Edad Moderna: la senda de la ininteligibilidad, de una ininteligibilidad de principio. Y la inaugura en el corazón mismo de su teoría de la sustancia.

En efecto, aquello a lo que «propiamente» corresponde el nombre de «sustancia», dado que es esencialmente infinito, se revela como incomprensible por su propia naturaleza. Lo infinito es absolutamente inaprehensible para todo entedimiento definido como finito. Se halla más allá de toda posibilidad de comprensión:

Y esto [que la idea de un ser soberanamente perfecto e infinito es verdadera] no deja de ser verdad, incluso aunque yo no comprenda lo infinito, o aunque haya en Dios una infi-

\footnotetext{
61 E incluso del sentido común de la época, al menos si aceptamos que éste transparece muy claramente en las concepciones de cuño teológico más difundidas en el momento. El cardenal Bérulle, muy próximo al círculo de Descartes, escribirá en uno de sus famosos Opúsculos lo siguiente: «Pues el hombre está compuesto de piezas completamente diferentes. Por una parte, es milagro, y, por otra, una nada. Es celeste por un lado, y terrestre por el otro. Es espiritual por una parte, y corporal por la otra. Es un ángel, es un animal, es una nada, es un milagro, es un centro, es un mundo, es un Dios, es una nada rodeada de Dios, indigente de Dios, capaz de Dios y colmado de Dios, si lo quiere» (Bérulle, Opuscules de piété (Opúsculo XXII, «De la création de l'homme»), París, Aubier, 1944, p. 199). Aunque no podemos desarrollar aquí esta hipótesis, tal vez no sea del todo descabellado comprender la metafísica cartesiana como sistematización filosófica, muy elaborada técnicamente, de dicho sentido común...
} 
nidad de cosas que yo no puedo comprender, ni tal vez tampoco alcanzar de ningún modo mediante el pensamiento. Pues es propio de la naturaleza de lo infinito que mi naturaleza, que es finita y limitada, no lo pueda comprender. ${ }^{62}$

Por ello mismo, porque la naturaleza infinita de Dios es indistinguible de su omnipotencia absoluta, tampoco podemos comprender cómo ni por qué crea Dios las cosas que crea; no podemos comprender el acto en función del cual Dios debía ser pensado como condición de la sustancialidad de las sustancias creadas 63 . La consecuencia, entonces, cae por su propio peso. Y es fundamental. La existencia misma de las cosas, de las sustancias creadas, se revelará también como algo de suyo, necesariamente, ininteligible. Para tratar de subsanar esta ininteligibilidad de principio, Descartes desplegará una reflexión que muy pronto se convertirá en teoría: la de la creación continua 64 .

Declarar, efectivamente, que toda criatura depende de la voluntad absolutamente libre, omnipotente, del Dios que la crea -decir, como hemos visto decir a nuestro autor, que «no hay ninguna cosa creada que pueda existir un solo momento sin ser sostenida y conservada» 65 por la potencia de Dios-, equivale a afirmar que la comprensión de la existencia de dichas criaturas -y que la duración de esa misma existencia- resulta por su misma esencia igualmente incomprensible. Pues tal existencia depende en todos sus momentos de un acto formal y materialmente idéntico al acto en virtud del cual el principio de todo lo que es instaura la esencia y la exis-

62 AT, IX-1, 37. Cf. también las respuestas a las quintas objeciones: «[...] es contradictorio que yo comprenda algo, y que eso que comprendo sea infinito; pues para tener una idea verdadera de lo infinito, no es de ninguna manera necesario que sea comprendido, y tanto más cuanto que la incomprensibilidad misma está contenida en la razón formal de lo infinito».

${ }^{63}$ Cf. AT, IX-1, 44: «[...] no debo asombrarme si mi inteligencia no es capaz de comprender por qué Dios hace lo que hace, y, así, no tengo ninguna razón para dudar de su existencia porque tal vez vea por experiencia muchas otras cosas sin poder comprender por qué razón ni cómo las ha producido Dios. Pues, como ya sé que mi naturaleza es extremadamente débil y limitada, y que, al contrario, la de Dios es inmensa, incomprensible e infinita, no tengo ya dificultad alguna para reconocer que hay una infinidad de cosas en su potencia cuyas causas sobrepasan el alcance de mi ingenio». Uno de los principales envites de la incomprensibilidad de la naturaleza divina será la supresión de las causas finales; si no podemos comprender por qué razón crea Dios las cosas, nunca podremos comprender cuáles son las causas finales de su creación. Descartes, sí, rechaza la investigación física de las causas finales, pero para reintroducir un cierto finalismo en su metafísica, reintroducción que no puede sino venir exigida por su concepción de la naturaleza y del creacionismo voluntarista divinos. Cf. AT, IX2, 37 (art. 28).

${ }^{64}$ Acerca de esta teoría, acerca de las tesis que harán suyas de una manera u otra prácticamente todos los cartesianos del XVII, cf. Sylavain Zac, L'idée de vie dans la philosophie de Spinoza, París, P.U.F., 1963, p. 26; É. Boutroux, De veritatibus aeternis apud Cartesium, op. cit., pp. 79-85; L. J. Beck, The Metaphysics of Descartes. A Study of the Meditations, Oxford, Clarendon Press, 1965, pp. 192-198; y B. Rousset, Spinoza lecteur des Objections faites aux Méditations de Descartes et de ses Réponses, París, Kimé, 1996, pp. 97-102.

65 AT, IX-2, 47. 
tencia de las cosas creadas; acto creador, en definitiva, que no es más inteligible que la naturaleza de su agente, pues coincide estrictamente con ella:

[...] una sustancia, para ser conservada durante todos los momentos que dura, necesita del mismo poder y de la misma acción que sería necesaria para producirla y crearla de nuevo si todavía no fuese. De suerte que la luz natural nos hace ver claramente que la conservación y la creación no difieren si no es respecto a nuestra forma de pensar, y no efectivamente 66

De la consideración de las sustancias creadas, finitas, como carentes de fuerza o de potencia propia para subsistir o conservarse, a su consideración como seres esencialmente imperfectos, no hay más que un paso mínimo. Afirmar la finitud e imperfección de las sustancias equivale a señalar directamente su dependencia respecto de la potencia de Dios; dependencia que no puede sino revelarse como constitutiva de lo creado en tanto que creado $67 . .$.

Así, la metafísica de Descartes se constituye bordeando siempre ciertas zonas de lo real que la reflexión considera como fundamentales pero que son estructuralmente ininteligibles para el hombre: la potencia de Dios, la naturaleza de su acto creador, y también la de su reflejo dentro del ámbito de la creación: la existencia de aquello que crea, de las criaturas, y también, consiguientemente, la naturaleza de la voluntad o libre albedrío del hombre. Éste debe ser aceptado - postulado más bienen virtud de un cierto testimonio de la experiencia interior de cada cual, pues se ve necesariamente sometido a los mismos problemas de ininteligibilidad observados a propósito de la naturaleza de la potencia divina y sus rendimientos. Nuestra comprensión se topa con un límite ciertamente infranqueable. El tope que señala o que establece el principio que ha dirigido en todo momento la reflexión y que se ha refractado en todos los objetos sobre los que ésta se ha vuelto: el creacionismo voluntarista divino.

En la profundización -en la discusión, a veces muy enconada- de todos estos problemas se construirá la metafísica de la sustancia más sistemática del siglo. Quizá pueda decirse por ello, con toda legitimidad, que ser anticartesiano en la primera Modernidad supone entregarse a la difícil tarea de romper con aquel espacio intelectual, con ese horizonte cuyos topoi más significativos diseña, organiza y lega

\footnotetext{
${ }^{66}$ AT, IX-1, 39. La idea no abandona ya nunca a Descartes. En los Principios insiste en lo mismo: «[...] es necesario que Dios sea el autor de mi existencia. Pues todo el tiempo de mi vida puede ser dividido en una infinidad de partes, ninguna de las cuales depende de ninguna manera de las otras; y así, del hecho de que un poco antes yo haya sido, no se sigue que deba ser ahora, a no ser que en este momento alguna causa me produzca y me cree, por así decir, nuevamente; es decir, que me conserve» (AT, IX-2, 39).

67 Cf. J.-M. Beyssade, Études sur Descartes, op. cit., p. 225.
} 
a su siglo nuestro autor, y cuya estructura es, más allá de toda duda razonable, esencialmente refractaria a todo intento de puesta en cuestión de una cierta concepción general del creacionismo divino y, sobre todo, de sus implicaciones en ética y antropología. O, lo que es lo mismo, a todo cuestionamiento de esta manera teorizada por Descartes de conceptualizar la voluntad, la potencia absoluta de Dios, y también, quizás más fundamental y decisivamente, de este modo de considerar la voluntad y la libertad -la potencia- humanas. Tales serán algunos de los problemas más emblemáticos de los suscitados por la metafísica de la sustancia que hemos rastreado en este estudio. Sólo Spinoza y Hobbes serán capaces de romper de manera absoluta con semejante espacio intelectual; sólo ellos redefinirán radicalmente estas polémicas. Y en verdad que pagarán un precio excesivo. El del desprecio en su forma teórica más absoluta: el de la ilegibilidad a que su reflexión, su crítica, es condenada sin remisión en su propia época. Pero esto, indudablemente, merece una investigación distinta de la ensayada en estas páginas...

Pedro Lomba Falcón

Departamento Historia de la Filosofía

Facultad de Filosofía

Universidad Complutense de Madrid

pedro.lomba@filos.ucm.es 